
\title{
3 Research Square \\ Title: GPC3 in the Exosomes from Hepatocellular Carcinoma HepG2 Cells
}

\section{Chunwen $\mathrm{Pu}$}

The Affiliated Sixth People's Hospital of Dalian Medical University

\section{Qi Wang}

The Affiliated Sixth People's Hospital of Dalian Medical University

\section{Aijun Sun}

The Affiliated Sixth People's Hospital of Dalian Medical University

\section{Ping Sun}

The Affiliated Sixth People's Hospital of Dalian Medical University

Hui Huang

The Affiliated Sixth People's Hospital of Dalian Medical University

Qiqi Zhang

The Affiliated Sixth People's Hospital of Dalian Medical University

\section{Xueying Sun}

The Affiliated Sixth People's Hospital of Dalian Medical University

\section{Zhidong Wang ( $\nabla$ pucw@Inhc.net.cn )}

The Affiliated Sixth People's Hospital of Dalian Medical University

\section{Yong Zhang}

The Affiliated Sixth People's Hospital of Dalian Medical University

\section{Research Article}

Keywords: Exosomes, Liver cancer, GPC3,Tumor microenvironment, Wnt / $\beta$-catenin signaling pathway

Posted Date: September 20th, 2021

DOl: https://doi.org/10.21203/rs.3.rs-656873/v1

License: (c) (1) This work is licensed under a Creative Commons Attribution 4.0 International License. Read Full License 


\section{Abstract \\ Background}

Exosomes play an important role in regulating the growth in normal and abnormal cells. Exosomes secreted from tumor cells are also involved in regulating the growth behaviors of normal cells and tumor cells.

\section{Methods}

HepG2 cells, LO2 and HepG2 cells with GPC3 knocked down using shRNA (HepG2-shGPC3), were treated with different concentrations of GPC3. The effects of different concentrations of GPC3 on cell growth and apoptosis were determined using CCK8 and flow cytometry. HepG2 exosomes (Exo) and exosomes of HepG2 cells with GPC3 knocked down using shRNA (shGPC3-Exo) were used to treat LO2 and HepG2 cells separately. Cell growth was measured by CCK8 kit. The cell cycle and apoptosis were measured by flow cytometry. The expression of GPC3/WNT3A/ $\beta$-catenin signal protein was determined by Western blotting.

\section{Results}

We found GPC3 has a two-way regulation between normal cells and HCC cells, which is the innovation of this research. After treating LO2 cells and HepG2 cells with GPC3, the LO2 cell cycle was blocked in the G0/G1 phase, while cell growth was inhibited and apoptosis was promoted; however, it appeared to promote the growth of HepG2 cells. Knocking down GPC3 can inhibit the growth and promote cell apoptosis of HepG2. In subsequent experiments, we found that GPC3 was expressed in both LO2 and HepG2 exosomes, and the expression of GPC3 in HepG2 exosomes is significantly higher than that of LO2 exosomes. These results suggested that GPC3 in exosomes has the potential to become a biomarker of HCC. In addition, HepG2 exosomes (Exo) can inhibit the growth of LO2 cells and promote apoptosis, which is consistent with the effect of GPC3 treatment. Further, we found that GPC3 in shGPC3-Exo had the same effect on LO2 cells as HepG2 exosomes (Exo), but the degree of influence was reduced. shGPC3-Exo showed a promoting effect on the growth of HepG2 cells. Therefore, GPC3 in exosomes plays a role in the growth of LO2 cells and HepG2 cells. Further studies have shown that GPC3 in liver cancer exosomes regulates the proliferation, apoptosis of LO2 and HepG2 cells through the Wnt / $\beta$ catenin signaling pathway.

\section{Conclusion}

GPC3 in the exosomes of liver cancer cells inhibits the growth of normal liver cells and promotes apoptosis by activating the Wnt/ $\beta$-catenin signaling pathway, and assists the occurrence and 
development of HCC.

\section{Introduction}

The incidence of liver cancer is the fifth highest among all cancers in the world. There were 905,700 new cases worldwide in 2020 , with a mortality rate as high as $90 \%^{[1]}$. Hepatocellular carcinoma (HCC) is the most common liver cancer, accounting for about $90 \%$ of all liver cancer cases ${ }^{[2]}$. HCC patients are usually diagnosed at an advanced stage and their survival rate is very low ${ }^{[3]}$. Early diagnosis and treatment are the key to improving the survival time of patients with liver cancer ${ }^{[4]}$. Thus, the identification of novel diagnostic markers for liver cancer is crucial.

Exosomes are membranous vesicles released into environment after fusion of intracellular multivesicular bodies and cell membranes. Tumor exosomes carry signaling molecules derived from tumor cells. They are involved in the regulation of normal and tumor cells, and reshaping the tumor microenvironment ${ }^{[5,6]}$. Tumor cell-derived exosomes participate in cell -cell communication to influence the uncontrolled growth, invasion and metastasis of tumor cells ${ }^{[7][8]}$. In addition, content in the exosomes from cancer patients provides opportunities for early diagnosis of cancer $^{[9-11]}$.

The heparin sulfate proteoglycan glypican-3 (GPC3) is involved in the regulation of cell proliferation, adhesion and migration ${ }^{[12,13]}$. Elevated GPC3 expression is detected in more than $70 \%$ of hepatocellular carcinoma $(\mathrm{HCC})^{[14]}$, and is often corelated with the metastasis of liver cancer. GPC3 promotes HCC growth through stimulating the classic wnt/ $\beta$-catenin signaling pathway while GPC3 expression knockeddown inhibits HCC cell proliferation and induces apoptosis ${ }^{[15]}$. Pei et al. found that autophagy attenuates the growth of HepG2 cells is associated with the inhibition of the GPC3/wnt/ $\beta$-catenin signaling ${ }^{[16]}$. In addition, GPC3 expression is often related to the poor prognosis of HCC patients ${ }^{[17]}$. Therefore, GPC3 is a suitable biomarker and prognostic factor for HCC, and targeted inhibition of GPC3 signaling may help control the proliferation and metastasis of HCC cells ${ }^{[18]}$.

Previous studies have shown that the expression of GPC3 in serum exosomes of HCC patients is significantly higher than that of hepatitis $B$ patients and healthy people ${ }^{[19]}$. This study explored the effect of GPC3 in HCC exosomes on the growth of HCC cells and on related signal pathways as well as the possible effect of GPC3 in tumor exosomes on normal liver cells and the impact of tumor microenvironment, which provides a theoretical basis for studying the occurrence and development of HCC.

\section{Result}

\section{Exosome purification and verification}

Previously, we found that the expression of GPC3 was elevated in liver cancer tissues compared with normal tissues. Nanoparticle tracking analysis (NTA) was performed with ZetaViewPMX 110 to observe 
the particle size of exosomes in the cell culture medium. The sample showed a vesicle structure with a diameter of about 50-150 nm, which was in line with the morphological characteristics of exosomes in the literature ${ }^{[20]}$ (Fig. 1A). Western blot results showed the presence of CD63 and TSG101, which were reported to be exosomal markers ${ }^{[21]}$ (Fig. 1B). The results indicated that exosomes have been successfully isolated from LO2 and HepG2 cell lines. In this study, we verified the expression of GPC3 in exosomes of LO2 and HepG2 cell lines by Western blot and the expression of GPC3 in liver cancer cell line HepG2 exosomes was more than that in normal liver cell line LO2 exosomes, which was consistent with the comparison of GPC3 expression in the two cells (Fig. 1C,D).

\section{The effect of GPC3 on the growth and apoptosis of normal cells}

Studies have shown that GPC3 promotes the development of liver cancer. In order to explore whether the effect of GPC3 on the growth of normal liver cells is different from that of liver cancer cells, we added GPC3 to LO2 and HepG2 cells to study the effects of different concentrations of GPC3 on cell growth. After adding different concentrations of GPC3, the growth of LO2 cells was inhibited, and the growth of HepG2 cells was promoted. The effect of GPC3 increased first and then decreased with the increase of concentration. GPC3 at a dose of $1 \mathrm{mg} / \mathrm{ml}$ had the most obvious effect on the two types of cells (Fig.2A). Flow cytometry analysis of Annexin V/PI staining also showed that apoptotic cells increased in LO2 cells after the addition of GPC3 at a concentration of $1 \mathrm{mg} / \mathrm{ml}$, while there was no difference in the level of apoptosis between GPC3 treated and untreated HepG2 cells (Fig.2B). Subsequently, we tested whether GPC3 affects cell growth through cell cycle arrest. As shown in Fig.2C, the addition of GPC3 resulted in an increase in the number percentage of the G0/G1 population of LO2 cells, resulting in G0/G1 block; on the contrary, the number percentage of the G0/G1 population decreased in HepG2 cells. These data indicated that GPC3 can inhibit the growth of normal cells by enhancing cell apoptosis and cell cycle arrest, while for HCC cells it can reduce cell cycle arrest to promote the growth of HCC cells, and not effect on cell apoptosis.

In order to further explore GPC3 function in the growth of HCC cells, the expression vector expressing the shRNA targeting GPC3 was transfected into HepG2 cells. After transfection, GPC3 expression in the HepG2 cells was decreased both at mRNA and protein levels compared with normal HepG2 cells (Fig. 3A-C). The growth of HepG2 cells was inhibited after GPC3 knockdown (Fig. 3D). Flow cytometry analysis of the cells stained with Annexin V/PI also showed an increase in apoptotic cells in the HepG2 cells with GPC3 knockdown (Fig. 3E). As shown in Fig. 3F, knockdown of GPC3 expression led to an increase of the percentage of the G0/G1 population in HepG2 cells, indicating a G0/G1 arrest. Next, we examined the effect of GPC3 on HCC cell invasion using the transwell assay. Our results thus indicated that GPC3 is involved in cell growth in HCC cells.

\section{GPC3 in exosomes stimulated the growth of HCC cells}


The previous study reported that GPC3 protein was found in serum exosomes from HCC patients ${ }^{[19]}$, which was corelated with GPC3 expression in HCC tissues. We then decided to examine the effect of GPC3 from the liver cancer exosomes on normal liver cells. Both LO2 and HepG2 cells were treated with the purified exosomes from the HepG2 control cells (Exo) and the HepG2 with GPC3 expression knocked down (shGPC3-Exo), respectively. The GPC3 content in the exosomes from the HepG2 cells with GPC3 expression knocked down was also decreased (Fig. 4A).

The growth of LO2 cells was significantly inhibited, which was concentration-dependent (Fig. 4B). shGPC3-Exo had the same inhibitory effect on the growth of LO2 cells, but the inhibitory effect is weakened, compared with the addition of Exo. shGPC3-Exo also promoted the growth of HepG2 cells in a dose-dependent manner (Fig. 4B). The results indicated that the migration effect of HepG2 exosomes on normal cells may be related to the dose of GPC3.

Flow cytometry analysis of Annexin V/PI staining showed that after treatment with $100 \mu \mathrm{g} / \mathrm{mL}$ Exo or shGPC3-Exo, the population of apoptotic cells in LO2 cells increased, and the effect of Exo group was more obvious than that of shGPC3-Exo group. The addition of shGPC3-Exo to HepG2 cells did not affect the number of apoptosis (Fig. 4C). Later, in the detection of the effect of exosomes on the liver cell cycle, it was found that the percentage of the number of LO2 cells G0/G1 population increased after the addition of the two groups of exosomes, showing G0/G1 blockade. The percentage of the number of HepG2 cells in the G0/G1 population decreased after shGPC3-Exo was added (Fig. 4D). This indicated that GPC3 in HepG2 cell exosomes can promote the apoptosis of LO2 cells, and may promote apoptosis by inhibiting the cell cycle of LO2 cells.

These data indicated that GPC3 in HCC exosomes may promote the apoptosis of normal hepatocytes, inhibit cell cycle and cell growth.

\section{GPC3 in liver cancer exosomes affects Wnt/ $\beta$-catenin signaling pathway in HCC cells}

Wnt/ $\beta$-catenin signaling pathway is involved in promoting the growth of HepG2 cells, and plays an important role in the occurrence, development and metastasis of liver cancer. Studies have shown that in liver cancer, GPC3 signals through the Wnt/ $\beta$-catenin signaling pathway ${ }^{[22]}$. Thus, we will investigated whether GPC3 in the exosomes from HepG2 cells activates the Wnt/ $\beta$-catenin signaling pathway.

First, we compared the expression of GPC3 and Wnt/ $\beta$-catenin signaling pathways in cells and exosomes. Western blot results showed that the content of GPC3 in LO2 cells was significantly less than that in HepG2 cells, and the expression levels of Wnt3a and $\beta$-catenin protein were also consistently less than that in HepG2 cells; and the expression levels of GPC3, Wnt3a and $\beta$-catenin protein in LO2 cell exosomes were also less than those in HepG2 cell exosomes.(Fig. 5A, B). 
Further studies revealed that the GPC3 content in LO2 cells increased significantly after GPC3 treatment, while Wnt3a and $\beta$-catenin protein increased; after Exo was added, the GPC3, Wnt3a and $\beta$-catenin protein content in LO2 cells also increased significantly. After shGPC3-Exo, the contents of GPC3, Wnt3a and $\beta$ catenin were increased compared with the control group LO2 cells, but the protein content was lower than that of Exo (Fig. 5C, D). It showed that GPC3 in HepG2 cell exosomes increased GPC3, Wnt3a and $\beta$ catenin protein content in LO2 cells. In the study of HepG2 cells, it was found that after knocking down the GPC3 in the cells, as the GPC3 in the cells decreased significantly, the content of Wnt3a and $\beta$-catenin protein decreased. After adding GPC3 to HepG2 cell culture, it was found that the content of GPC3 and $\beta$ catenin protein increased significantly, and the content of Wnt3a also increased (Fig. 5C, D). After adding shGPC3-Exo, the contents of GPC3, Wnt3a and $\beta$-catenin in HepG2 cells increased compared with the control group.

The results of these studies indicated that the levels of GPC3 and Wnt/ $\beta$-catenin signaling protein in normal liver cells are significantly lower than those in liver cancer cells. GPC3 in liver cancer cell exosomes can activate Wnt/ $\beta$-catenin signaling pathway by increasing GPC3 in normal liver cells.

\section{Discussion}

The "Global Cancer Report 2020" published by the WHO pointed out that there are more than 900,000 liver cancer patients worldwide and 830,000 death $s^{[1]}$. The leading cause of death in patients with liver cancer is tumor progression and metastasis. The tumor microenvironment determines the type of liver cancer ${ }^{[23]}$, because tumor-specific markers carried by tumor exosomes participate in cell communication in the tumor microenvironment, and are related to the growth and invasion ability of tumor cells. In recent years, researchers have found that the expression rate of Glypican-3 in liver cancer tissues has gradually and significantly increased with the increase of clinical stages ${ }^{[24]}$. We also discovered increased levels of Glypican-3 in the blood of liver cancer patients. Huixia Di et al. also found that compared with healthy people and hepatitis B patients, the expression of GPC3 in serum exosomes of HCC patients can be detected and the content is significantly increased ${ }^{[19]}$, indicating that liver cancer cells can secrete GPC3 into the blood circulation. We noticed in vitro experiments that GPC3 was expressed in normal liver cells, HCC cells and their exosomes, and the GPC3 content in exosomes of HCC cell was significantly higher than that in normal liver cell exosomes. It showed that when GPC3 promotes the metastasis of liver cancer cells, it may also carry out cell communication with normal liver cells, affecting the growth of normal liver cells, thereby helping the metastasis of tumor cells. Therefore, elucidating the role of GPC3 in hepatocytes and signal transduction pathways in exosomes may provide a theoretical basis for revealing the development process of liver cancer and determining new early diagnosis methods.

Shanshan W et al. found that GPC3 showed a significant promoting effect in the growth and migration of HCC cells ${ }^{[25]}$, which is consistent with our experimental results. In this research, we discovered that the number of apoptosis of HCC cells remains unchanged after GPC3 is added, but the number of apoptosis of HCC cells increased after GPC3 gene knockdown. Therefore, GPC3 in HCC cells may inhibit cell 
apoptosis. This is the first time we have discovered that GPC3 inhibits the growth of normal hepatocytes by blocking the cell cycle and significantly promotes their apoptosis. Therefore, GPC3 may help HCC cell growth by inducing normal liver cell apoptosis and growth, and further promote the development of liver cancer. GPC3 was found stimulating the growth of HCC cells by increasing the autocrine/paracrine pathway and activating the canonical Wnt signaling pathway ${ }^{[15]}$. We noticed that for normal liver cells, GPC3 also activates the classic wnt / $\beta$-catenin signaling pathway, which further promotes the occurrence of HCC.

Exosomes transmit information through the contents of vesicles ${ }^{[26]}$. Exosomes secreted by tumor cells can regulate surrounding or distant non-tumor cells to form a pre-metastasis microenvironment ${ }^{[27,28]}$ to promote tumor cell metastasis. We next tested whether GPC3 in liver cancer exosomes can perform its function in normal liver cells. The optimal concentration of liver cancer exosomes $(100 \mu \mathrm{g} / \mathrm{mL})$ to promote growth acts on liver cell lines. In normal liver cells, liver cancer exosomes can significantly inhibit growth, block cell cycle, and promote apoptosis. After the decrease of GPC3 content in liver cancer exosomes, the effect on normal cells is reduced, which proves that the exosomes of liver cancer GPC3 can inhibit the growth of normal liver cells and promote apoptosis. The above results indicate that the content of GPC3 in liver cancer cell exosomes is significantly higher than that of normal liver cell exosomes, while GPC3 in liver cancer cell exosomes inhibits the growth of normal liver cells, promotes apoptosis, which can contribute to the development of HCC.

The activation of the Wnt signaling pathway is one of the most common molecular events related to the progression of HCC. Further studies have shown that the Wnt signaling pathway is essential for GPC3mediated cell growth ${ }^{[29]}$. However, the regulatory mechanism of GPC3 in HCC exosomes involved in HCC cell growth is still unclear. In this study, we proved that GPC3 and wnt / $\beta$-catenin signaling protein exist in the exosomes of normal hepatocytes and HCC cells, and the content of wnt / $\beta$-catenin signaling protein is significantly lower than that in cells. GPC3 in the exosomes of $\mathrm{HCC}$ cells can activate the Wnt/ $\beta$-catenin pathway of normal hepatocytes, and the effect is reduced after adding HepG2-shGPC3-exo, which is consistent with the trend of adding GPC3. This further proves that GPC3 in HCC cell exosomes activates the Wnt / $\beta$-catenin pathway in normal liver cells, thereby promoting the occurrence of HCC.

\section{Conclusion}

This study shows that GPC3 is enriched and expressed in liver cancer exosomes. It not only regulates the cell cycle of HCC, but also inhibits the growth of normal hepatocytes, and activates the Wnt / $\beta$-catenin pathway in normal hepatocytes, thereby promoting the occurrence and development of HCC.

\section{Methods}

\section{Cell Culture}


All cells were purchased from Type Culture Collection of the Chinese Academy of Sciences (Shanghai, China). HepG2 cell variants were cultured and passaged in the MEM medium supplemented with 0.4 $\mathrm{mg} / \mathrm{ml} \mathrm{G418}$ and 10\% FBS. LO2 cells were cultured and passaged in the RPMI-1640 medium supplemented with $1 \% \mathrm{P} / \mathrm{S}$ and $10 \% \mathrm{FBS}$ at $37^{\circ} \mathrm{C}$ and $5 \% \mathrm{CO} 2$. GPC3 protein was purchased from CUSABIO (Wuhan, China).

\section{Exosome Isolation}

Isolation of exosomes was carried out at $4^{\circ} \mathrm{C}$. The collected medium was centrifuged at $300 \mathrm{~g}$ for 10 minutes to remove cell pellets. The supernatant then was centrifuged at $2000 \mathrm{~g}$ for 4 minutes and 10 minutes to remove dead cells. Then, the supernatant was centrifuged at $10,000 \mathrm{~g}$ for 30 minutes to remove cell debris. Finally, the supernatant was centrifuged at $100,000 \mathrm{~g}$ for $70 \mathrm{~min}$ to obtain exosomes.

\section{ZetaView Analysis}

The pellet washed with $30 \mathrm{~mL} 1 \times$ PBS, resuspend in $250 \mu \mathrm{L} 1 \times \mathrm{PBS}$ and stored at $-80^{\circ} \mathrm{C}$. ZetaViewPMX 110 (Particle Metrix, Meerbusch, Germany) and the corresponding software ZetaView8.04.02 were used to perform Nanoparticle Tracking Analysis (NTA) in Shanghai VivaCell to measure the size of exosomes.

\section{The enzyme-linked immunosorbent assay (ELISA) analysis}

According to the manufacturer's instructions, GPC3 ELISA Kit was used to measure the GPC3 level with the CUSABIO's human GPC-3 as a standard. All experiments were performed in triplicates.

\section{Lentivirus, Plasmid, Cell Transfection and Infection}

The lentivirus genOFFTM st-h-GPC3 (CGACACCCTTTGCTGGAAT) containing shRNA for GPC3 was designed and constructed by Siwega (Wuhan, China). The HepG2 cells were infected with lentivirus (hU6MCS-CBh-gcGFP-IRES-puromycin GV493). After the infection time reaches 5 days, the cells are extracted and RNA is collected for PCR detection

\section{Quantitative real-time PCR}

The cellular and exosomal RNA was extracted with TRIzol, the first-strand CDNA and random primers were synthesized using the iScript cDNA Synthesis Kit (Bio-Rad, USA). QPCR was performed using the CFX96 real-time PCR detection system (Bio-Rad, USA) and the iTaqTM universal SYBR Green Supermix (Bio-Rad, USA). The mRNA content was normalized with the housekeeping gene GAPDH. Table I summarized the primer sequences for all RT-qPCR. The reaction conditions were: $95^{\circ} \mathrm{C}$ for 5 minutes, then the CFX Connect system at $95^{\circ} \mathrm{C}$ for 10 seconds and $60^{\circ} \mathrm{C}$ for 30 seconds. According to the $2-\Delta \Delta \mathrm{Cq}$ method, the RT-qPCR results were normalized to GADPH. 
Table 1

QPCR primer sequence

\begin{tabular}{|ll|}
\hline Primer & Sequence $\left(\mathbf{5}^{\prime}\right.$ to $\mathbf{3}^{\prime}$ ) \\
\hline Hu-GAPDH -F & ACAACTTTGGTATCGTGGAAGG \\
\hline Hu-GAPDH -R & GCCATCACGCCACAGTTTC \\
\hline Hu-GPC3-F & GAAACAGTCAGCAGGCAAC \\
\hline Hu-GPC3-R & GAAGCACACCACCGAGA \\
\hline
\end{tabular}

\section{Cell growth assay}

LO2 cells, HepG2 and HepG2-shGPC3 cells were seeded into 96-well plates at a density of $3-5 \times 10^{4}$ cells/well, and then treated with various concentrations of GPC3 or Exo. After incubating at $37^{\circ} \mathrm{C}$ for 48 hours, add $10 \mu \mathrm{L}$ of CCK-8 solution to each well of the culture medium and mix well to ensure the color uniformity in the well. After continuing to incubate for $4 \mathrm{~h}$, the absorbance was measured directly at $450 \mathrm{~nm}$. The percentage of survival cells for each treatment was calculated as (OD value of test group/OD value of control group) $\times 100 \%$.

\section{Flow Cytometry Analysis}

The cells seeded in a 6 -well plate at a total of $1 \times 10^{5} /$ well and treated with purified GPC3 protein or the exosomes derived from HepG2 cells or the exosomes from the HepG2-shGPC3 cells Twenty-four hours after treatment, the Annexin V / PI detection kit (BD Biosciences) and cell cycle staining kit (MultiSciences) were used to examine cell apoptosis and cell cycle. All data were then analyzed with BDAccuri® soft ware.

\section{Western blot analysis}

Samples collected were lysed in a mixed extraction reagent containing a protease and a phosphatase inhibitor, and the lysate was centrifuged $\left(12,000 \mathrm{rpm}, 5 \mathrm{~min}, 4^{\circ} \mathrm{C}\right)$. The supernatant was collected and at $80^{\circ} \mathrm{C}$. Protein concentrations were determined using the Bradford assay. Samples were electrophoresed in $12 \%$ SDS-PAGE and transferred to nitrocellulose membranes. After being blocked with $5 \%$ skim milk in PBS containing $0.1 \%$ Tween 20 (PBST), the membranes were incubated with antibodies. Next, the membranes were incubated with peroxidase-conjugated antibodies (proteintech,1:8,000) and treated with Electro-Chemi-Luminescence. Western blot analysis was performed using the antibodies: CD63 (1:1000, abcam), TSG101 (1:1000, abcam), GPC3 (1:1000, bioss), WNT3A (1:1000, HuaBio), $\beta$-Catenin (1:1000, HuaBio) and GAPDH (1:10000, abcam).

\section{Statistical analysis}

The data were expressed as the mean \pm SEM. The student's $t$ test (two-tailed) or one-way ANOVA followed by Tukey's multiple comparisons test were used. All calculations were performed using Graphpad Prism software. 


\section{Abbreviations}

GPC3, glypican-3; Exo, Exosomes; shGPC3-Exo,HepG2 exosomes that have silenced GPC3

\section{Declarations}

\section{Acknowledgements}

The authors thank Wei Zou and Zhaoyi Wang, for their contribution to the editing the final revision, review and critical suggestions for improvement.

\section{Authors' contributions}

ZDW, CWP and YZ proposed and guided this research. QW, HH, PS, QQZ and XYS performed the experiments. QW and CWP collected and analyzed the data. QW, HH, PS, QQZ, XYS and AJS contributed to the design of the study and further drafts. ZDW, CWP and YZ revised the manuscript. All authors read and approved the final version of the manuscript.

\section{Funding}

The authors disclosed receipt of the following financial support for the research, authorship, and/or publication of this article: This work was supported by Natural Science Foundation Guidance Program Project of Liaoning Province (20180550784), Natural Science Foundation Guidance Program Project of Liaoning Province (2019-ZD-1003).

\section{Availability of the data and materials}

The datasets and the reagents used in this study are available from the corresponding author upon reasonable request.

\section{Ethics approval and consent to participate}

Not applicable.

\section{Consent for publication}

Not applicable.

\section{Competing Interests}

The authors have declared that no competing interest exists.

\section{References}

1. International Agency for Research on Cancer:Liver. World Health Organization (WHO) 2020. 
2. Llovet JM, Zucman-Rossi J, Pikarsky E, Sangro B, Schwartz M, Sherman M, Gores G. Hepatocellular carcinoma. Nat Rev Dis Primers 2016; 2: 16018.

3. Cao H, Phan H, Yang LX. Improved chemotherapy for hepatocellular carcinoma. Anticancer Res 2012; 32(4): 1379-1386.

4. Kudo M. Emerging strategies for the management of hepatocellular carcinoma. Dig Dis 2014; 32(6): 655-657.

5. Meckes DG, Jr. Exosomal communication goes viral. J Virol 2015; 89(10): 5200-5203.

6. Tkach M, Thery C. Communication by Extracellular Vesicles: Where We Are and Where We Need to Go. Cell 2016; 164(6): 1226-1232.

7. Le MT, Hamar P, Guo C, Basar E, Perdigao-Henriques R, Balaj L, Lieberman J. miR-200-containing extracellular vesicles promote breast cancer cell metastasis. J Clin Invest 2014; 124(12): 5109-5128.

8. Costa-Silva B, Aiello NM, Ocean AJ, Singh S, Zhang H, Thakur BK, Becker A, Hoshino A, Mark MT, Molina H, Xiang J, Zhang T, Theilen TM, Garcia-Santos G, Williams C, Ararso Y, Huang Y, Rodrigues G, Shen TL, Labori KJ, Lothe IM, Kure EH, Hernandez J, Doussot A, Ebbesen SH, Grandgenett PM, Hollingsworth MA, Jain M, Mallya K, Batra SK, Jarnagin WR, Schwartz RE, Matei I, Peinado H, Stanger BZ, Bromberg J, Lyden D. Pancreatic cancer exosomes initiate pre-metastatic niche formation in the liver. Nat Cell Biol 2015; 17(6): 816-826.

9. Melo SA, Luecke LB, Kahlert C, Fernandez AF, Gammon ST, Kaye J, LeBleu VS, Mittendorf EA, Weitz J, Rahbari N, Reissfelder C, Pilarsky C, Fraga MF, Piwnica-Worms D, Kalluri R. Glypican-1 identifies cancer exosomes and detects early pancreatic cancer. Nature 2015; 523(7559): 177-182.

10. Corcoran C, Friel AM, Duffy MJ, Crown J, O'Driscoll L. Intracellular and extracellular microRNAs in breast cancer. Clin Chem 2011; 57(1): 18-32.

11. Skog J, Wurdinger T, van Rijn S, Meijer DH, Gainche L, Sena-Esteves M, Curry WT, Jr., Carter BS, Krichevsky AM, Breakefield XO. Glioblastoma microvesicles transport RNA and proteins that promote tumour growth and provide diagnostic biomarkers. Nat Cell Biol 2008; 10(12): 1470-1476.

12. Haruyama $\mathrm{Y}$, Kataoka H. Glypican-3 is a prognostic factor and an immunotherapeutic target in hepatocellular carcinoma. World J Gastroenterol 2016; 22(1): 275-283.

13. Sung YK, Hwang SY, Park MK, Farooq M, Han IS, Bae HI, Kim JC, Kim M. Glypican-3 is overexpressed in human hepatocellular carcinoma. Cancer Sci 2003; 94(3): 259-262.

14. Baumhoer D, Tornillo L, Stadlmann S, Roncalli M, Diamantis EK, Terracciano LM. Glypican 3 expression in human nonneoplastic, preneoplastic, and neoplastic tissues: a tissue microarray analysis of 4,387 tissue samples. Am J Clin Pathol 2008; 129(6): 899-906.

15. Capurro MI, Xiang YY, Lobe C, Filmus J. Glypican-3 promotes the growth of hepatocellular carcinoma by stimulating canonical Wnt signaling. Cancer Res 2005; 65(14): 6245-6254.

16. Hu P, Cheng B, He Y, Wei Z, Wu D, Meng Z. Autophagy suppresses proliferation of HepG2 cells via inhibiting glypican-3/wnt/beta-catenin signaling. Onco Targets Ther 2018; 11: 193-200. 
17. Shirakawa H, Suzuki H, Shimomura M, Kojima M, Gotohda N, Takahashi S, Nakagohri T, Konishi M, Kobayashi N, Kinoshita T, Nakatsura T. Glypican-3 expression is correlated with poor prognosis in hepatocellular carcinoma. Cancer Sci 2009; 100(8): 1403-1407.

18. Hippo $Y$, Watanabe $K$, Watanabe A, Midorikawa $Y$, Yamamoto S, Ihara S, Tokita S, Iwanari H, Ito Y, Nakano K, Nezu J, Tsunoda H, Yoshino T, Ohizumi I, Tsuchiya M, Ohnishi S, Makuuchi M, Hamakubo T, Kodama T, Aburatani H. Identification of soluble NH2-terminal fragment of glypican-3 as a serological marker for early-stage hepatocellular carcinoma. Cancer Res 2004; 64(7): 2418-2423.

19. Di H, Mi Z, Sun Y, Liu X, Li A, Jiang Y, Gao H, Rong P, Liu D. Nanozyme-assisted sensitive profiling of exosomal proteins for rapid cancer diagnosis. Theranostics 2020; 10(20): 9303-9314.

20. Yuan R, Zhi Q, Zhao H, Han Y, Gao L, Wang B, Kou Z, Guo Z, He S, Xue X, Hu H. Upregulated expression of miR-106a by DNA hypomethylation plays an oncogenic role in hepatocellular carcinoma. Tumour Biol 2015; 36(4): 3093-3100.

21. Baranyai T, Herczeg K, Onodi Z, Voszka I, Modos K, Marton N, Nagy G, Mager I, Wood MJ, El Andaloussi S, Palinkas Z, Kumar V, Nagy P, Kittel A, Buzas El, Ferdinandy P, Giricz Z. Isolation of Exosomes from Blood Plasma: Qualitative and Quantitative Comparison of Ultracentrifugation and Size Exclusion Chromatography Methods. PLoS One 2015; 10(12): e0145686.

22. Gao W, Ho M. The role of glypican-3 in regulating Wnt in hepatocellular carcinomas. Cancer Rep 2011; 1(1): 14-19.

23. Seehawer M, Heinzmann F, D'Artista L, Harbig J, Roux PF, Hoenicke L, Dang H, Klotz S, Robinson L, Dore G, Rozenblum N, Kang TW, Chawla R, Buch T, Vucur M, Roth M, Zuber J, Luedde T, Sipos B, Longerich T, Heikenwalder M, Wang XW, Bischof O, Zender L. Necroptosis microenvironment directs lineage commitment in liver cancer. Nature 2018; 562(7725): 69-75.

24. Sun B, Huang Z, Wang B, Yu Y, Lin S, Luo L, Wang Y. Significance of Glypican-3 (GPC3) Expression in Hepatocellular Cancer Diagnosis. Med Sci Monit 2017; 23: 850-855.

25. Wang S, Chen N, Chen Y, Sun L, Li L, Liu H. Elevated GPC3 level promotes cell proliferation in liver cancer. Oncol Lett 2018; 16(1): 970-976.

26. Gele AA, Qureshi SA, Kour P, Kumar B, Diaz E. Barriers and facilitators to cervical cancer screening among Pakistani and Somali immigrant women in Oslo: a qualitative study. Int J Womens Health 2017; 9: 487-496.

27. Peinado H, Alec kovic M, Lavotshkin S, Matei I, Costa-Silva B, Moreno-Bueno G, Hergueta-Redondo M, Williams C, Garcia-Santos G, Ghajar CM, Nitadori-Hoshino A, Hoffman C, Badal K, Garcia BA, Callahan MK, Yuan J, Martins VR, Skog J, Kaplan RN, Brady MS, Wolchok JD, Chapman PB, Kang Y, Bromberg J, Lyden D. Corrigendum: Melanoma exosomes educate bone marrow progenitor cells toward a pro-metastatic phenotype through MET. Nat Med 2016; 22(12): 1502.

28. Yu Z, Zhao S, Ren L, Wang L, Chen Z, Hoffman RM, Zhou J. Pancreatic cancer-derived exosomes promote tumor metastasis and liver pre-metastatic niche formation. Oncotarget 2017; 8(38): 6346163483. 
29. Wu Y, Liu H, Ding H. GPC-3 in hepatocellular carcinoma: current perspectives. J Hepatocell Carcinoma 2016; 3: 63-67.

30. Huang H, Zhou Z, Li H, Zhang Y, Zhao L, Wang Z, Zhang Q, Liu C, Han C, Wang Q, Pu C, Zou W. Downregulation of ER-alpha36 mRNA in serum exosomes of the patients with hepatocellular carcinoma. Clin Transl Med 2020; 10(1): 346-352.

\section{Figures}

A

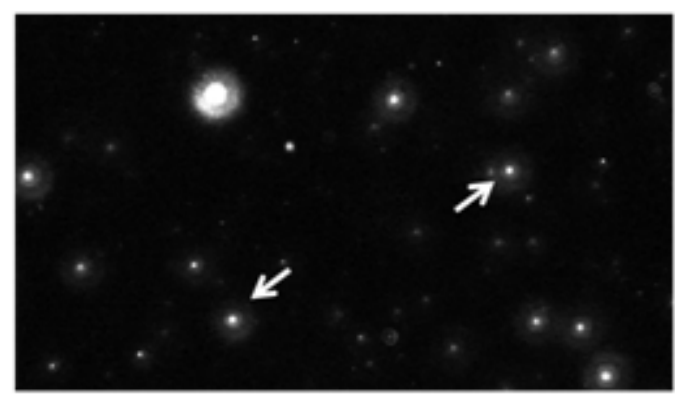

B

CD63

TSG101

GAPDH
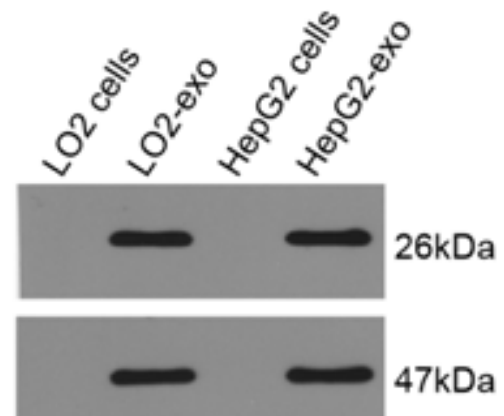

$47 \mathrm{kDa}$

$36 \mathrm{kDa}$
C

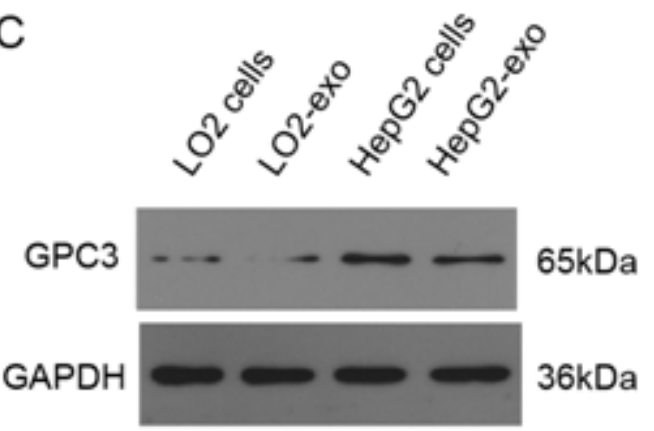

D

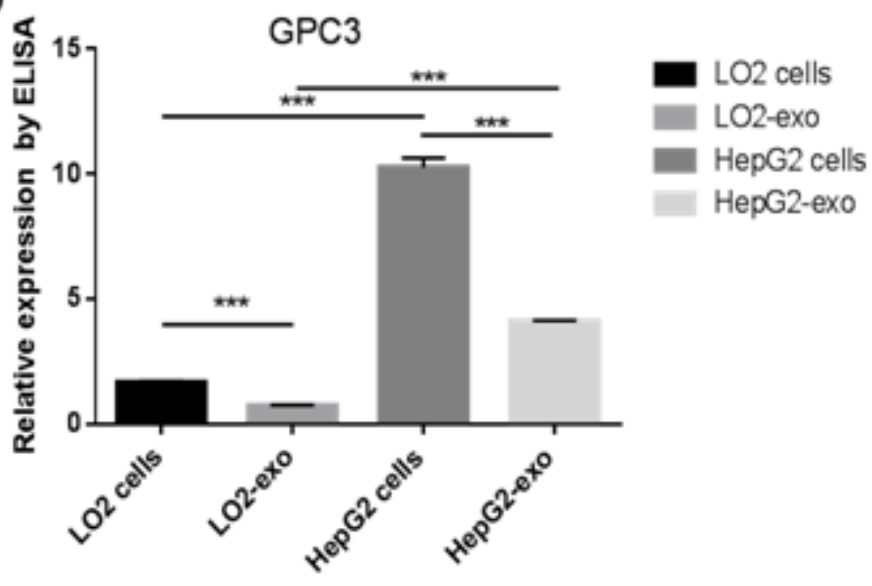

\section{Figure 1}

Characterization of the exosomes derived from LO2 cells and HepG2 cells. (A) ZetaView detected images of exosomes in cell culture media (Scale bars,100 nm). (B) Western blot analysis showed the expression of two exosomal markers of CD63 and TSG101 in the exosome-rich medium. (C) Western blot and (D) ELISA detected the expression of GPC3 in cells and exosomes derived from LO2 and HepG2 cells. (***P $<0.001, \mathrm{n}=3$ ). 

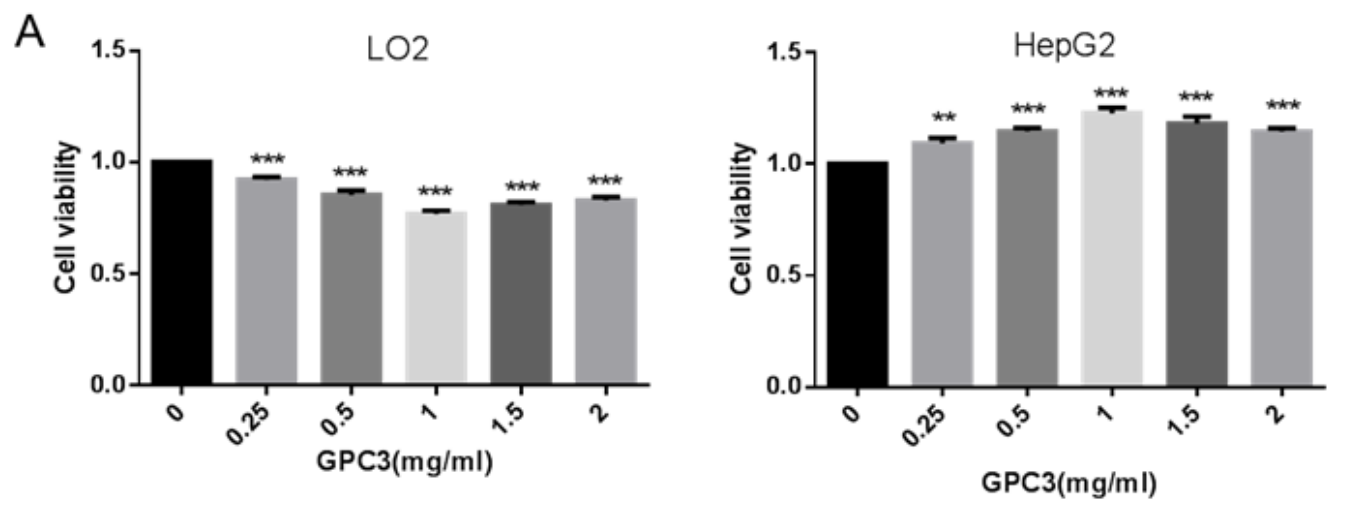

B
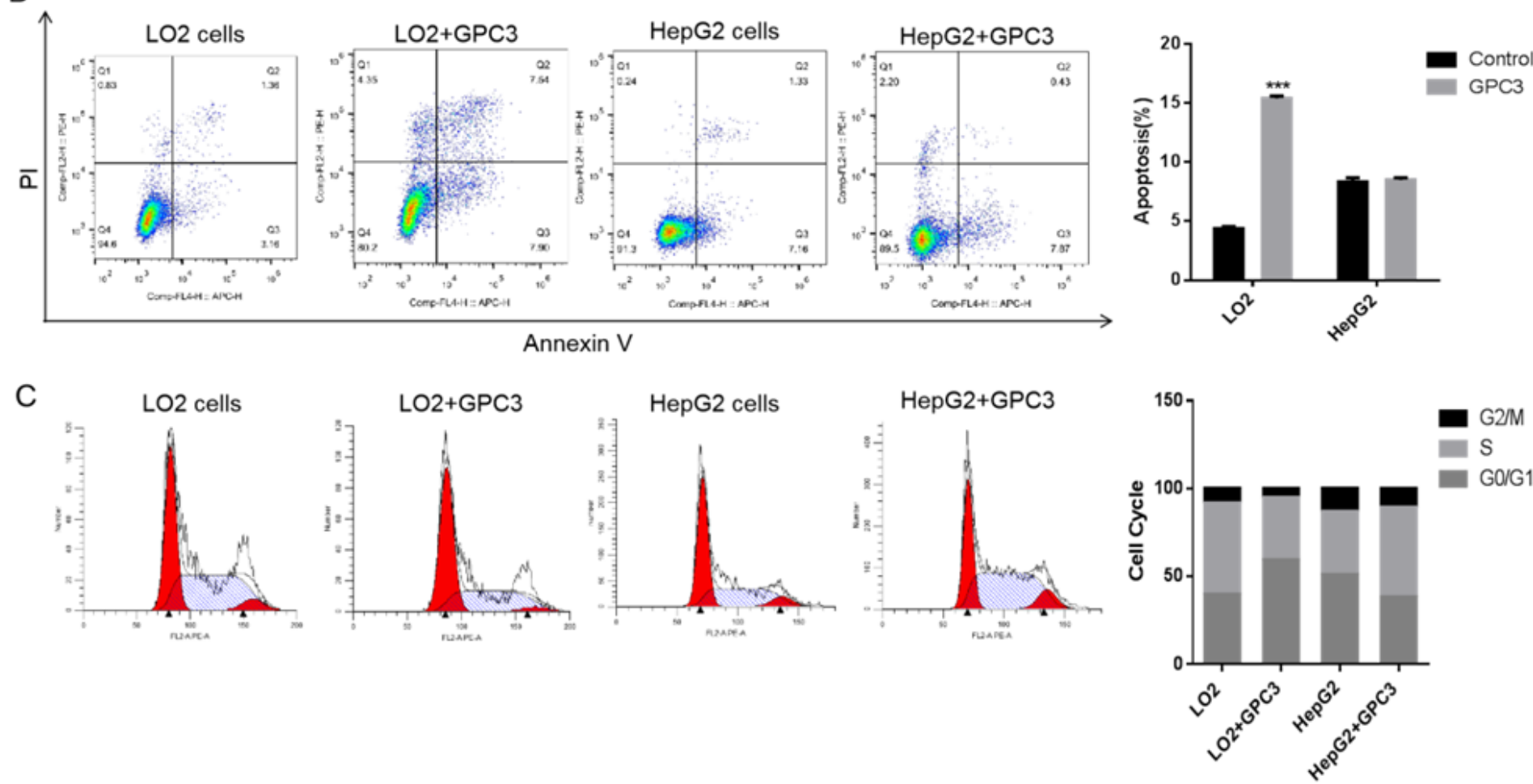

Figure 2

The effect of GPC3 on the growth of HCC cells. (A) The cell growth activity of LO2 and HepG2 cells was determined by GPC3 treatment. (B) FITC-Annexin V/PI analysis was performed in LO2 and HepG2 cells treated with GPC3. The FC analysis of Annexin V showed that apoptotic cells increased in LO2 cells treated with GPC3. (C) cell cycle analysis showed that the G0/G1 population increased in LO2 cells treated with GPC3, and decreased in HepG2 cells. The data were expressed as mean \pm standard error. ( ${ }^{\star} P<0.05,{ }^{*} \mathrm{P}<0.01,{ }^{\star \star *} \mathrm{P}<0.001, \mathrm{n}=3$ ). Untreated cells (Control), GPC3 treated LO2 cells, or HepG2 cells (LO2+GPC3/HepG2+GPC3). 


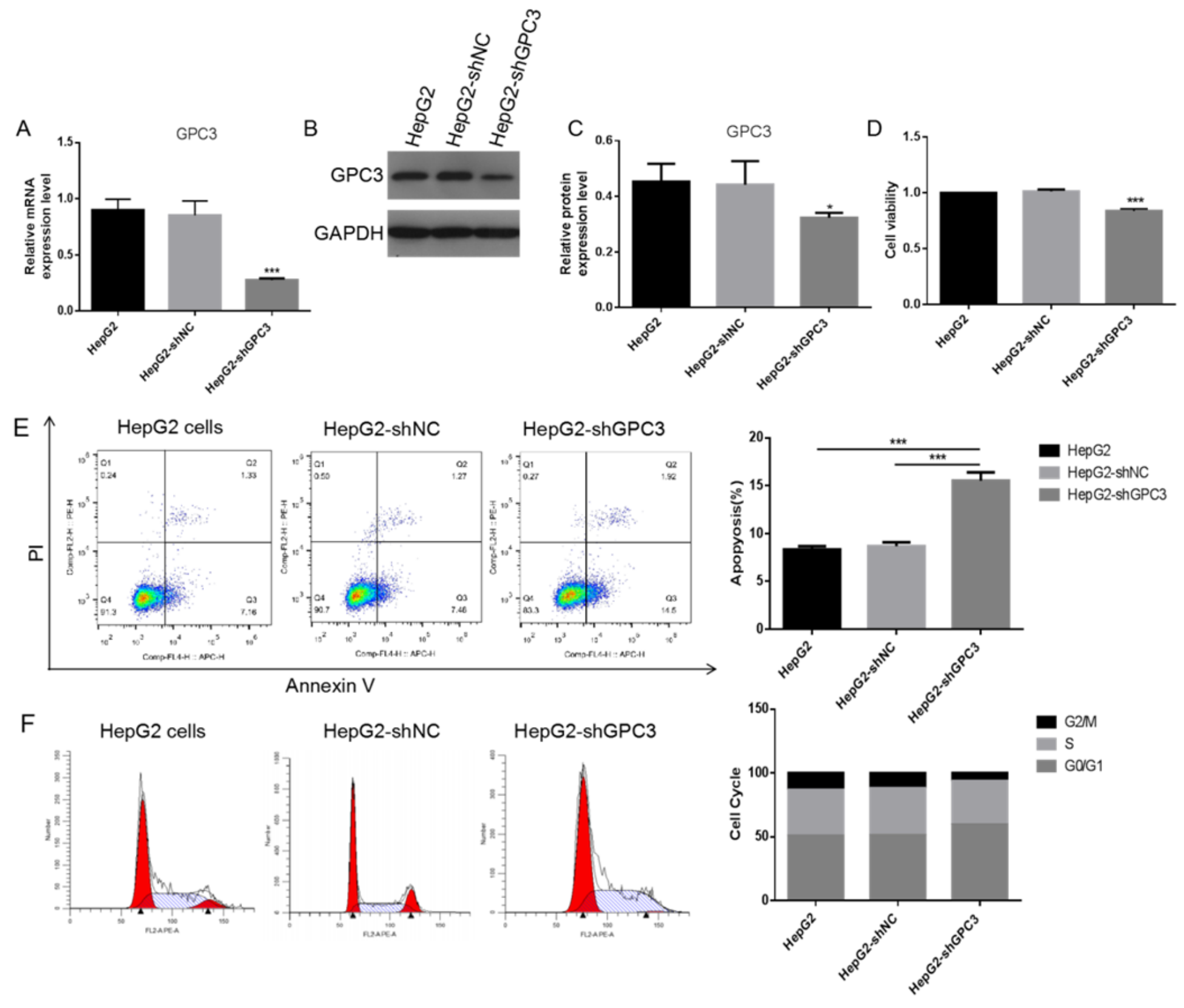

Figure 3

Knockdown of GPC3 attenuated the growth of HCC cells. (A). GPC3 mRNA expression in the HepG2 cells transfected with the GPC3 shRNA was measured with fluorescence qPCR. (B) \& (C). Western blot analysis of GPC3 protein expression in the HepG2 cells transfected with GPC3 shRNA. (D). Cell growth of the HepG2 cells with GPC3 expression knocked down. (E). FITC-Annexin V/PI analysis of the HepG2 cells with knockdown of GPC3 expression. (F). Cell cycle analysis of the HepG2 cells with the knockdown of GPC3 expression. The data are expressed as mean \pm standard error. HepG2 cells with GPC3 expression knocked down (HepG2-shGPC3). ( ${ }^{\star} P<0.05,{ }^{\star *} P<0.01$, ${ }^{\star * * P}<0.001$ HepG2 vs HepG2-shGPC3, $n=3$ ). 

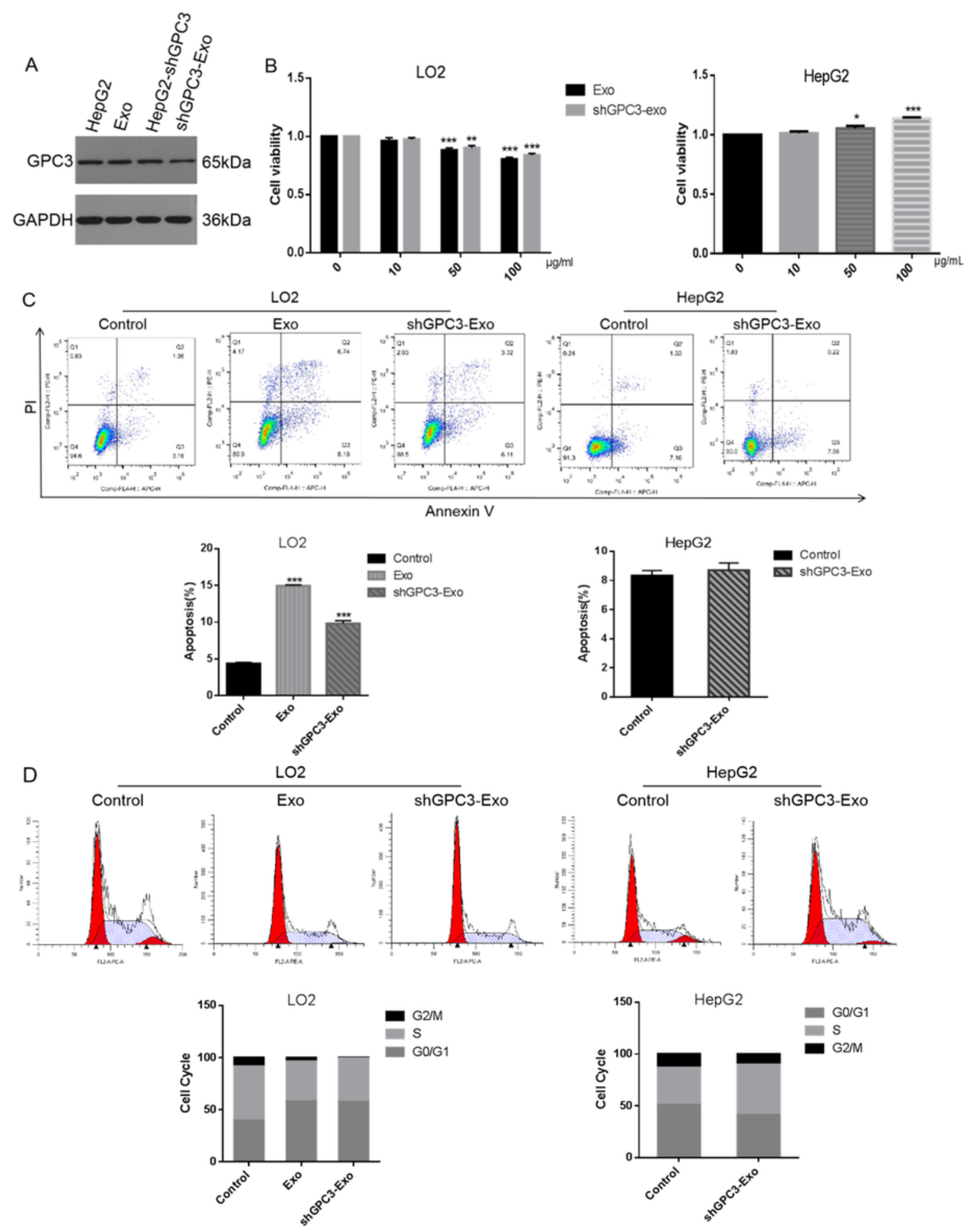

Figure 4

The effect of GPC3 in liver cancer exosomes on the growth of LO2 and HCC cells. (A) Western blot was used to determine the level of GPC3 protein in HepG2 cells and exosomes with or without GPC3 knockdown. (B) The cell growth activity of LO2 and HepG2 cells was determined by treatment with or without GPC3 knockdown HepG2 cell exosomes. ( ${ }^{\star} p<0.05$, ${ }^{\star *} p<0.01$, ${ }^{\star \star *} p<0.001$ vs $0, n=3$ ). (C) FITCAnnexin V / PI analysis was performed in LO2 and HepG2 cells treated with exosomes. (D) Cell cycle 
analysis showed that the G0/G1 population increased in LO2 cells treated with exosomes, but decreased in HepG2 cells. The data are expressed as mean \pm standard error. $\left({ }^{\star} p<0.05,{ }^{\star *} p<0.01,{ }^{\star \star \star} p<0.001\right.$ vs Control $n=3$ ). Untreated cells(Control), HepG2 exosomes treated (Exo) LO2 and HepG2, GPC3 knockdown HepG2 exosomes (shGPC3-Exo) treated LO2 and HepG2.

A
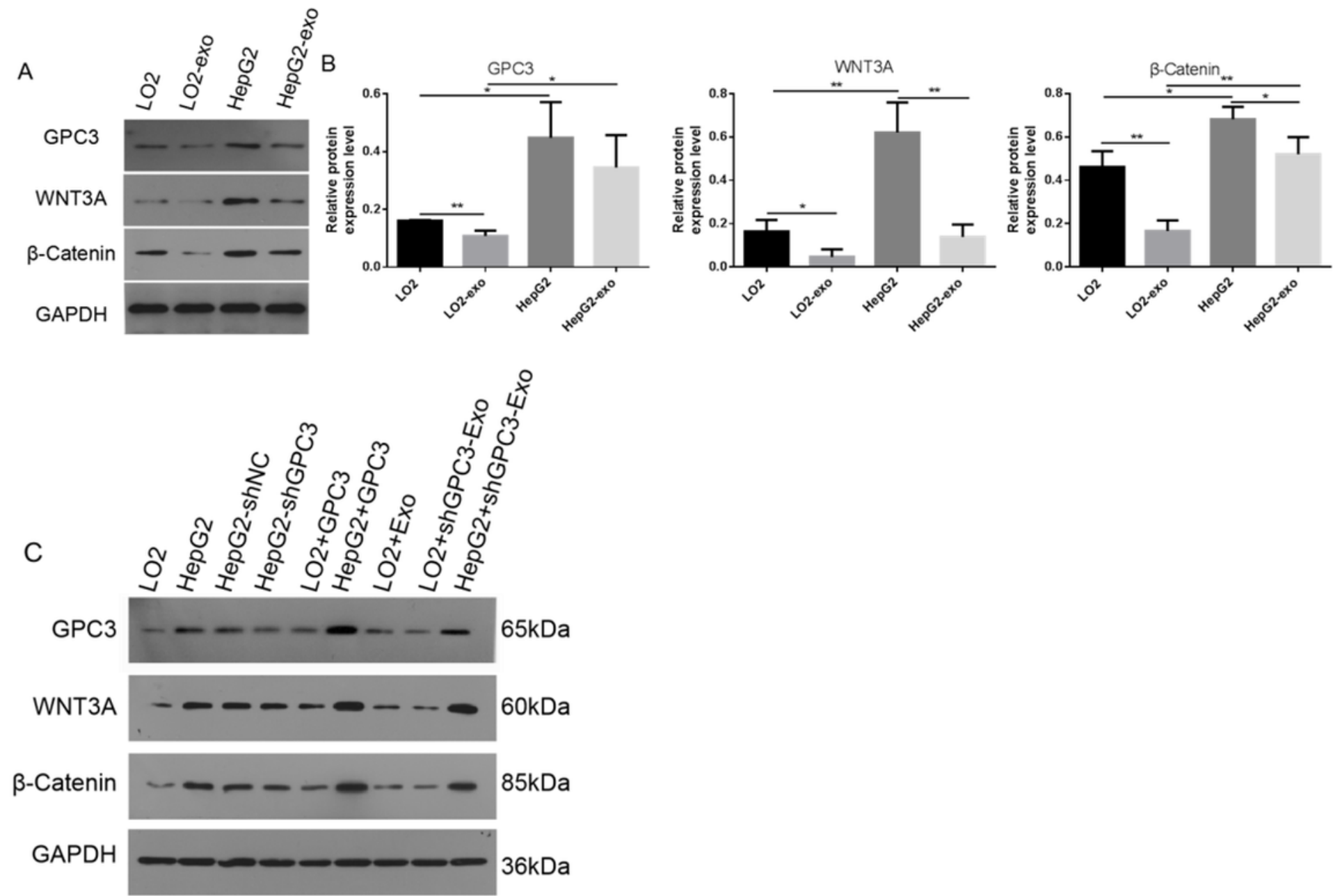

D

GPC3

WNT3A

$\beta-$ Catenin
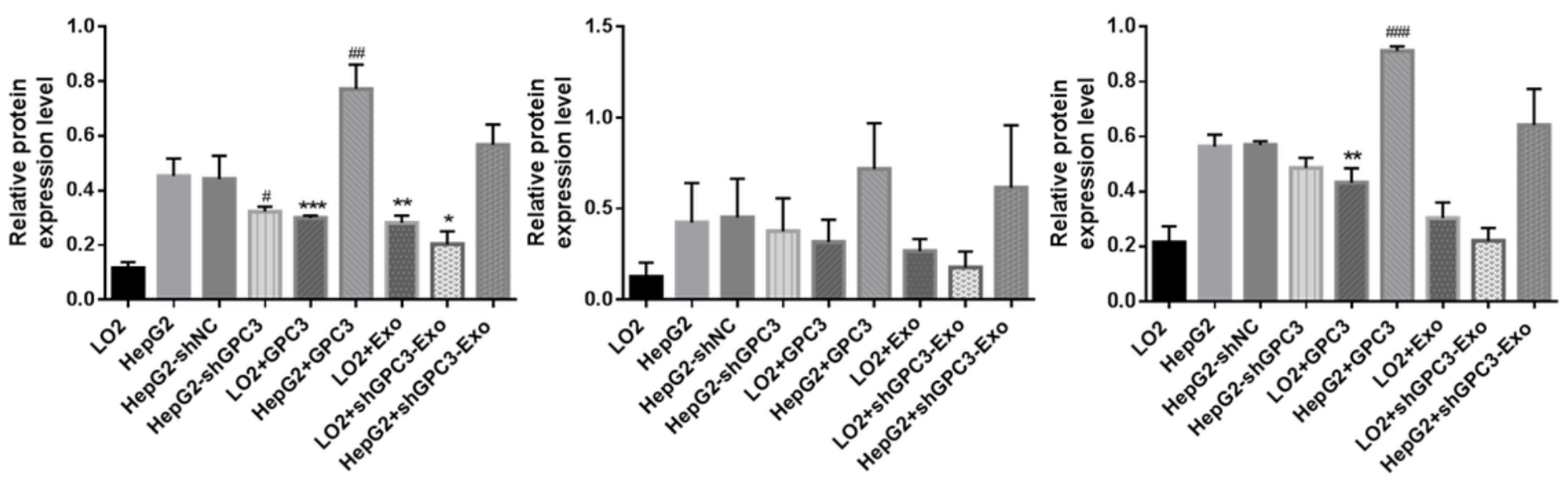

Figure 5 
Exosomal GPC3 affects the growth of normal hepatocytes and HCC cells through Wnt/ $\beta$-catenin. (A) and (B) determined the expression level of GPC3 in LO2 and HepG2 cells and exosomes by Western blot analysis. ( ${ }^{\star} p<0.05,{ }^{*} p<0.01,{ }^{\star} \times * P<0.001, n=3$ ). (C) and (D), under the influence of GPC3 in different ways, the expression levels of GPC3, WNT3A and $\beta$-catenin in LO2 and HepG2 cells were determined by Western blot analysis. ${ }^{\star} p<0.05,{ }^{\star *} p<0.01,{ }^{\star \star *} p<0.001$ vs. LO2; $\# p<0.05, \# \# p<0.01$ vs. HepG2. $n=3$ ). The data are expressed as mean \pm standard error. 